\title{
Green Capitalism: Democratizing Sustainable Innovation by Recycling Intellectual Capital Energy
}

\author{
Evangelos Markopoulos ${ }^{1,2}$, Emma Luisa Gann ${ }^{1}$, Ines Selma Kirane ${ }^{1}$, \\ Hannu Vanharanta ${ }^{3,4}$ \\ ${ }^{1}$ HULT International Business School, Hult House East, 35 Commercial Rd, E1 1LD, \\ London, United Kingdom \\ ${ }^{2}$ Turku University of Applied Sciences. Faculty of Engineering and Business \\ Joukahaisenkatu 3, ICT-City, C-wing, FI-20520 Turku, Finland \\ ${ }^{3}$ University of Vaasa, School of Technology and Innovations, Wolffintie 34, 65200 \\ Vaasa, Finland \\ ${ }^{4}$ Poznań University of Technology, Plac Marii Skłodowskiej-Curie 5, 60-965 \\ Poznań, Poland \\ evangelos.markopoulos@faculty.hult.edu,kinesselma01@gmail.com, \\ emma.gann@hotmail.de,hannu@vanharanta.fi
}

\begin{abstract}
Climate change and global warming are posing a threat to the planet's biodiversity placing the world's population at risk. For many years, NGOs, Governmental bodies and entrepreneurs have tried to tackle social and global environmental challenges by the roots through direct action. Nonetheless, those initiatives often fail to achieve short-term, mid-term and long-term impacts, turning out as ineffective solutions to the urgent environmental challenges. The problem lies in the nature of those initiatives as their main objective are solutions for the world's problems, denying and rather taunting any profitability aspirations. This paper introduces the concept of Green Capitalism which describes how firms can increase profitability by inventing sustainable products/services. It introduces a new way of thinking, based on the Democratic New Product Development (DeNPD) Model in an effort to reduce non-marketable idea wastage and transform it into profitable sustainable innovation with the contribution and participation of the society and individuals.
\end{abstract}

Keywords: New Product Development · Green Ocean · Company Democracy, Holacracy $\cdot$ Sustainability $\cdot$ Environment $\cdot$ Innovation $\cdot$ Knowledge $\cdot$ Management $\cdot$ New Product Development $\cdot$ People $\cdot$ Intellectual Capital

\section{Introduction}

Unlike the NGOs, capitalistic organizations, are bottom-line driven and often contrarily detached from the bigger picture such as environmental issues, poverty, justice, peace, etc. However, due to the continuous efforts of activists, the last decades have brought a massive rise in environmental consciousness amongst consumers. Therefore, in order to stay competitive in the future, firms must acknowledge the sustainable expectations 
of their customers and incorporate sustainability in their practices. In traditional organizations, sustainable product knowledge derives primarily from the R\&D departments. This kind of human capital usage limitation restricts the efforts to design sustainable products and services. By moving into a Holacratic R\&D approach, other experts in the organization can also contribute to the R\&D efforts with knowledge and skills per case. This can be extended into a democratic R\&D approach, with the knowledge contribution of every employee on specific R\&D projects activities. However, and when it comes to sustainable innovation the society which is often neglected, can play a significant role in what is sustainably relevant. This transformation can be achieved through the Democratic Green Product Development Model (DeGPD).

This paper introduces the concept of Green Capitalism which describes how firms can increase profitability by inventing sustainable products. It also introduces a new way of thinking, based on the Democratic New Product Development (DeNPD) in an effort to reduce idea wastage as non-marketable, and transform it into profitable sustainable innovation with the contribution and participation of the society. Organizations of any size and in any industry can achieve this transformation by using the DeGPD as a tool towards reaching Green Oceans.

The model recognizes and utilizes the contribution of the society as an industry partner with better understanding and empathy for environmental issues, able to make better judgments about the relevance of a product compared to investors or other capitaldriven decision-makers. The model operates on six levels in a tryptic pyramid structure, representing the relationship of a product's success, with the contribution of the society in sustainable product development, the product's sustainable value acceptance, and the organization's contribution index to sustainable development. The DeGPD, within the concept of reducing knowledge wastage through the contribution of the society, can turn traditional blue ocean-oriented capitalism into green ocean-oriented, or simply into Green Capitalism, offering value to the economy, the society and the environment, by saving the planet profitably.

\section{Challenges and Risks of the Green Economy}

With the steady and alarming rise of the global ecological footprint, organizations and governments attempt to collaborate on framing sustainable global solutions. Despite achievements such as consensual targets agreed upon in several summits, forces of change do not solely rely on international actions. Indeed, consumers, companies and local institutions are gaining awareness around the possibility of engaging in and building a green economy. The term 'sustainability' became increasingly popular, a business opportunity for some companies, and a marketing buzzword for others. Transitioning from short-term business actions to long-term sustainable investments is crucial. The need for transformational change means changing the old and embracing the new, by being bold and innovative with committed to taking actions [1]. However such transformation faces significant challenges in strategy and actions.

Historically, managers have regarded environmental initiatives as utterly opposing to profit aspirations [2]. Producing sustainable products/services is indeed costly from many dimensions starting from the supply chain, to the raw materials, the manufactured sustainably, the reduction or zero usage of harmful chemicals, labor costs, acquisition of third-party certification labeling sustainable products, compliance with regulations 
and standards environment, healthy etc.[3]. As a result, many companies attempt to avoid sustainability measures, fearing it could affect their business operations strategy, production speed and volume, product/service pricing, productivity, profitability, performance and competitiveness. Therefore companies that commit to environmental impacts, need to place their products in the market for a high price to sustain the profit margins to be financially sustainable and viable.

Expensive products, however (ie. fair trade consumer discretionary products), make consumers, especially those facing financial constraints without motives and means to return to the environment, reluctant towards sustainable products which seem more of a luxury than an ethical act, and a lifestyle for the privileged ones who can afford them. The environmentally friendly market has been narrowed to the ones privileged to afford green products, limiting the ability to reduce prices, increase demand, increase the markets, impact more people and indeed return to the environments with the help of many and not the few. Therefore there are real challenges in the Green Economy to be solved, starting by making green products affordable.

\section{The Role of Society in Sustainable Innovation}

Despite the fact that environmental awareness concerned the world after the second world war, it is only the last decade that the society and the governments have been significantly active to contribute to this global threat and concern. In the 1960s, the concern about environmental sustainability was raised as a response to critical traffic congestions, which was the result of the increasing car ownership in the 1950s [4]. The public started to engage in protests to raise awareness and make it a government concern. Political actions regarding environmentalism are primarily based on natural resources consumption but rarely placed into a societal context [5]. Green activism efforts of the late 20th century did not have enough outreach to carry the spark needed on consumerism by society.

Due to the intensification of the climate crisis in recent years, environmental efforts are being propelled by the younger generations. International movements like Fridays for Future [6] in which children abandon school duties in order to strike for the climate in 150 countries have raised awareness across the globe as a multi-generational concern, highlighting consequences of such negligence. Relayed in modern platforms, the global citizen movements gained momentum. Consequently, consumers' expectations evolved from utility and commoditization to shared-value contribution. Today people are keen to sacrifice cheap prices if in return they can satisfy their conscience and contribute towards climate change preventing. In order to respond to those customer changing demands, more companies incorporate sustainability into their processes and product portfolios. It seems that the degree of environmental sustainability of companies is essential to the financial sustainability they shall have in the future. Henceforth, the society can possibly make a large-scale environmental impact by influencing political decision-making through large scale activism, and by influencing the new product development by changing, if not imposing, their consumption habits and expectations. 


\section{The Green Ocean Strategy}

The concept of Green Strategies has been floating in the literature for quite some time without consensus on the term itself, the practices to design and apply such strategies and the practical tools needed to support them. In 2019, E. Markopoulos, I. S. Kirane et. al. theorized the Green Ocean Strategy in an extended and upgraded version of the Blue Ocean Strategy. This strategy goes beyond the simple and theoretical cliché of 'thinking outside the box', 'think different', 'think lateral', 'flip the question', etc. The model aims to create sustainable market spaces, while perpetually maintaining the relevance of the company, providing a more holistic approach to the organizations that are floating today on Green Oceans by relating fair trade with social development. To effectively sail on Green Oceans, companies need to achieve the triptych of going Green by designing and implementing Social, Economic and Environmental strategies. Green transformation requires practical tools to be elaborated in the Green strategies that can create a bond with their customer base through added-value innovations, which must be profitable and successful enough to drive into market dominance. Green Ocean Strategy (Fig. 1) is executed with tools and practices, such as the 3S Matrix for strategy development and implementation, provided in the Turquoise canal, the transition phase from Blue to Green, offering the opportunity to organizations to achieve sustainable corporate transformation in products, services and operations.

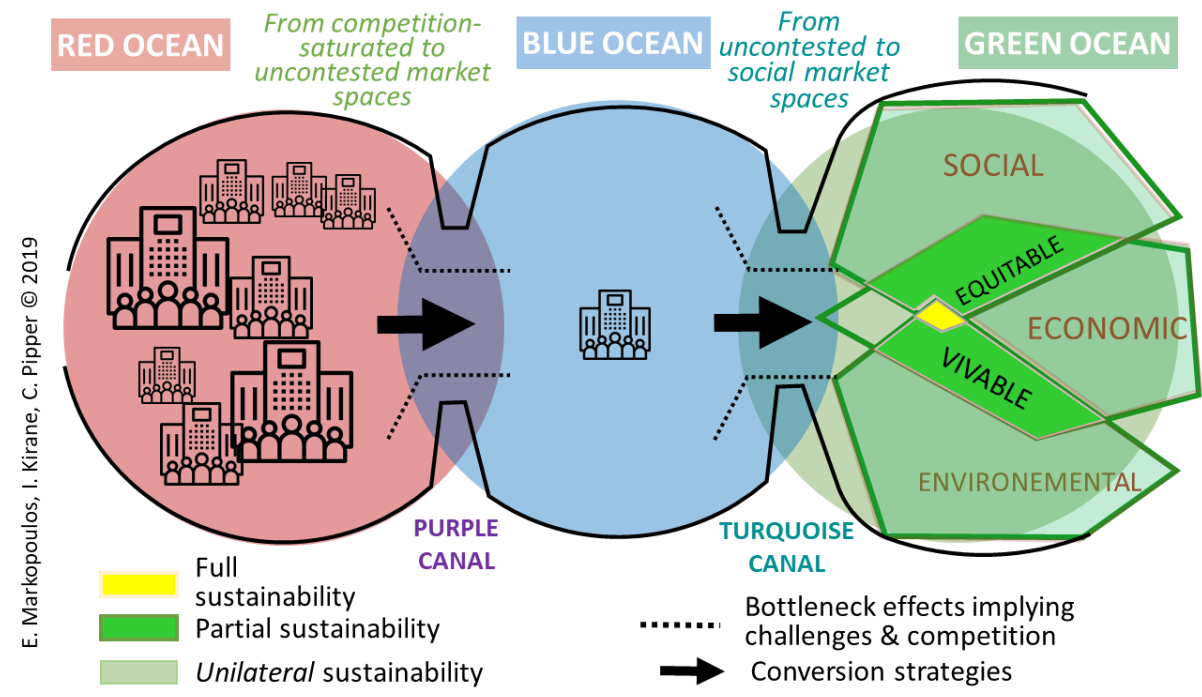

Fig. 1. The Green Ocean Strategy, a transition process for long-term profitability.

\section{The Green Innovation Waste Management Protocol (GIWMP)}

The practical effectiveness and success of a Green Ocean Strategy is determined by the number, value and impact new green products and services are developed, but also 
the utilization of the knowledge that did not become part of the Green Ocean elements that composed the strategy. Knowledge and innovation of any form is a result of energy placed in thought, actions and results in attempts to improve people's lives under any dimension. The knowledge that does not get applied, for any reason, is a waste of intellectual energy that humanity and society can not afford to lose or ignore. Intellectual energy is related to an extend to environmental energy from the resources used to develop it over small or long periods of time.

Therefore, as knowledge is a valuable intellectual capital produced with physical and mental energy, must be preserved, recycled, and certainly not wasted. To achieve such a goal, the Green Ocean Strategy addresses this challenge with the Green Innovation Waste Management Protocol (GIWMP). The protocol is executed under a conceptual framework aiming to reduce knowledge wastage by guiding companies to achieve more efficient idea generation for sustainable product development, contributing to the Green Oceans Strategy initiatives. GIWMP operates within the integration of the Democratic Green Product Development Model (DeGPD) and the Green Ocean Strategy by integrating the society in a new Green product development process. Following the Social Enterprise Design Thinking Model, GIWMP measures the number of ideas and knowledge generated over the three innovation evolution phases of Inspiration, Ideation and Implementation for new product development under a Green Ocean Strategy perspective (Fig. 2).

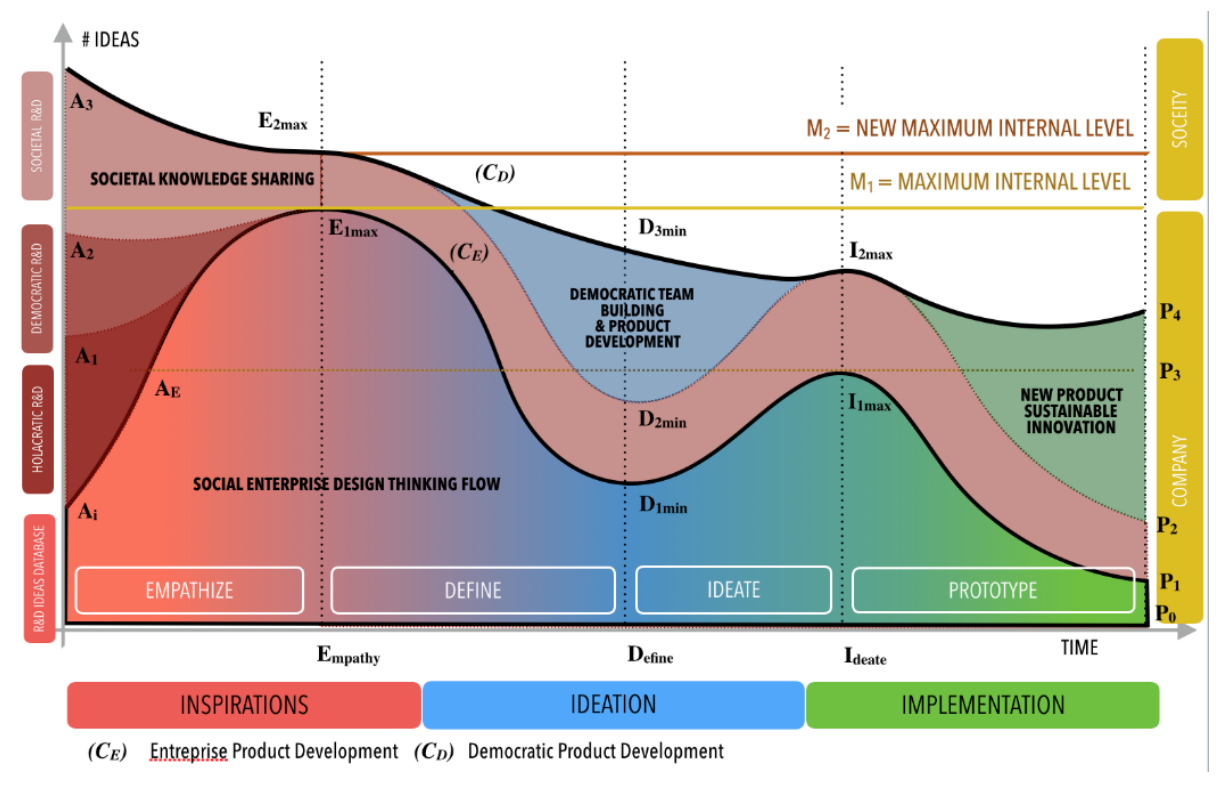

Fig. 2. The Green Innovation Waste Management Protocol (GIWMP)

\subsection{GIWMP Innovation Evolution Phases}

The GIWMP evolves over three phases. The first phase 'Innovation' evolution phase is the Inspiration linked with the Red Ocean Strategy [7] and defined as the known 
market space with defined industry boundaries in which companies try to obtain a greater share of the existing market by outperforming their rivals. In product development, tis derives from the comparative analysis related to the market (stakeholders, competitors, socio-economic frame).

The second phase 'Ideation' is linked to the Blue Ocean Strategy where there is a simultaneous pursuit low-cost of differentiation to establish new demand and market spaces. It is the state where the possibilities to extend opportunities outside the current environment are considered.

The third phase 'Implementation' is linked with the Green Ocean Strategy. It is the space were products/services extend from innovation ideation to sustainable implementation. This phase enables the creation of sustainable market spaces while making the company perpetually relevant. This phase aligns the whole system of the firm's activities with its human intellectual capital for differentiation and low-cost. [8]

\subsection{GIWMP Product Development Timeline}

The Product Development Timeline in the GIWMP protocol elaborates on the basis of the Social Enterprise Thinking Model, converging both the Design Thinking Model and the Human-Centered Design Model [9]. The GIWMP graph is being expressed on the basis of the Number of Ideas/Knowledge (y) per amount of time (x). Specifically:

Initial point (where $\mathrm{y}=\mathrm{A}_{\mathrm{i}}$ and $\mathrm{x}=0$ ): Refers to the number of knowledge already available in the R\&D department of the company, coming from previous market research, prototypes, surveys, customer feedback reports, etc. The distance $\mathrm{y}=\mathrm{A}_{\mathrm{i}}$ can be expressed as the R\&D Knowledge Database.

First ascendant curve $\left(C_{E}\right.$; where $\left.0 \leq x \leq E\right)$ : Refers to the Inspiration phase in the literal sense or popular understanding: the R\&D team usually brainstorms a set number of ideas $\left(C_{E}\right.$ from $A_{i}$ to $\left.A_{E}\right)$, followed by a phase where employees and engineers amplify the brainstorming stage via ideas interpretation $\left(C_{E}\right.$ from $A_{E}$ to $\left.E_{1 \max }\right)$.

First maximum of the curve $\left(\mathrm{C}_{\mathrm{E}}\right.$ at point $\left.\mathrm{E} 1_{\max }\right)$ : Refers to the culminant moment of the $\mathrm{R} \& \mathrm{D}$ phase when a large volume of ideas is being pooled. The graph gets tangent to the maximum internal level $\left(\mathrm{M}_{1}\right)$ of the company ideas (yellow line).

The Initial Point, first ascendant curve, and the first maximum of the curve are part of the Inspiration phase and complete the Empathy phase. Empathy is necessary for adequate inspiration ideas-providers must understand their targeted audience. As a result, the R\&D process will be truly answering the evolving needs and changing wants of the customers.

The first descendant curve $\left(\mathrm{C}_{\mathrm{E}}\right.$; where $\left.\mathrm{E} \leq \mathrm{x} \leq \mathrm{D}\right)$ : Refers to the transition phase between Inspiration \& Ideation. When ideas are turned into projects, there is a natural and necessary selection process where ideas with high success probability enter the Ideation stage. In this phase conditions, parameters and variables are expressed and defined. The 'Definition' phase is a transition between 'Inspiration' and the 'Ideation'.

First minimum of the curve $\left(C_{E}\right.$ at point $\left.D_{1 \min }\right)$ : Refers to the end of the Definition phase, when the ideas selection ends after one or many meetings and the number of ideas to be realizable has been reduced to a level noted $\mathrm{D}_{1 \mathrm{~min}}$. It is the state which generates Blue Ocean Strategy due to the mindset change achieved at this instance where the R\&D team starts thinking outside the box to integrate a level of innovativeness to the retained ideas. 
Second ascendant curve $\left(C_{E}\right.$; where $\left.D \leq x \leq I\right)$ : Refers to the pure Ideation phase, the moment when the R\&D phase conceptualizes how to transform intangibility and tangibility. This natural increase of ideas, due to the Blue Ocean Strategy mindset, and the fact that tangible conceptualization requires innovativeness in the process of fabrication, marketing strategies, etc, might alter the output of the initial idea.

The second maximum of the curve $\left(\mathrm{C}_{\mathrm{E}}\right.$ at point $\left.\mathrm{I}_{\mathrm{m} \text { max }}\right)$ Refers to the end of the Ideation phase, where a significantly higher number of ideas generated, combining pure outputs and engineering processes.

Second descendent curve $\left(\mathrm{C}_{\mathrm{E}}\right.$; when $\left.\mathrm{I} \leq \mathrm{x} \leq \mathrm{P}_{0}\right)$ : Refers to the prototyping phase where the actual fabrication of variants of the output gets to be commercialized. In a regular product development process, portfolio ideas are significantly reduced due to the optimal selection process based on financials, assets capabilities, contacts, legal compliance, etc

While the 'Definition' and 'Ideate' instances are part of the Ideation phase in general, the prototyping is part of the implementation phase.

\subsection{GIWMP Process Democratization Plan}

The Process Democratization Plan in the GIWMP refers to the aggregate of areas beneath the $C_{D}$ curve and above the $C_{E}$ curve. The $C_{D}$ Curve refers to the desired Democratic Product Development curve, while the $\mathrm{C}_{\mathrm{E}}$ curve refers to the Enterprise Product Development curve (or classic product development). The areas and the company's behavior results from the Holacratic R\&D, the Democratic R\&D and the Societal R\&D. Holacratic R\&D: Holacratic management is a new growing corporate culture trend. Transforming the R\&D units management under the holacratic principles of continuously rotating research participants per case and project [10] provides an additional initial level of ideas generation $\left(\Delta \mathrm{H}=\mathrm{A}_{1}-\mathrm{A}_{\mathrm{i}}\right)$ compared to the traditional $\mathrm{R} \& \mathrm{D}$ management methods [11]

Democratic R\&D: Democratic management where knowledge contributions can derive from anyone and at any time, substantially increases ideas through the use of the Company Democracy Model $\left(\triangle \mathrm{CDM}=\mathrm{A}_{2}-\mathrm{A}_{1}\right)$. CDM is a knowledge elicitation model that transforms human intellectual capital contributions from basic ideas to disruptive innovation products and services. [12]

Societal R\&D: Societal R\&D is the ultimate level of organizational openness and maturity to engage third parties and benefit from their contributions. Societal R\&D implementation allows internal as well as external thinkers, engineers, and domain-experts to provide their ideas through the DeNPD approach. The Societal Knowledge Sharing allows the Company to achieve a higher level of Ideas than their maximum internal level $\left(\mathrm{A} 3>\mathrm{M}_{1}\right)$.

This three-stage knowledge democratization roadmap allows a wider spectrum of ideation, and acts as a benchmark for marketing research (identifying evolving needs, wants, habits, etc.) and avoiding innovation myopia. Sustained growth depends on how broadly people define their business, and how carefully they gauge their customer needs [13]. Optimizing the Ideation phase with the participation of the entire organization first and the society after that though democratization, amplifies the level of commercialization realized per number of ideas (or prototypes) through the new product sustainable innovation. 


\section{Green Capitalism Through the DeNPD Model}

The utilization of the society as a knowledge generation engine for green product ideas is based on the ethical, effective and rewarding integration of the citizens through a democratic process. An approach to achieve this challenge is the Democratic New Product Development Model (DeNPD) (Fig. 3), which provides the framework on bringing ideas from the society into a company [14]

\section{The COMPANY DEMOCRACY Model for NEW PRODUCT DEVELOPMENT COMMITMENT VS BENEFITS VS SUCCESS CASES}

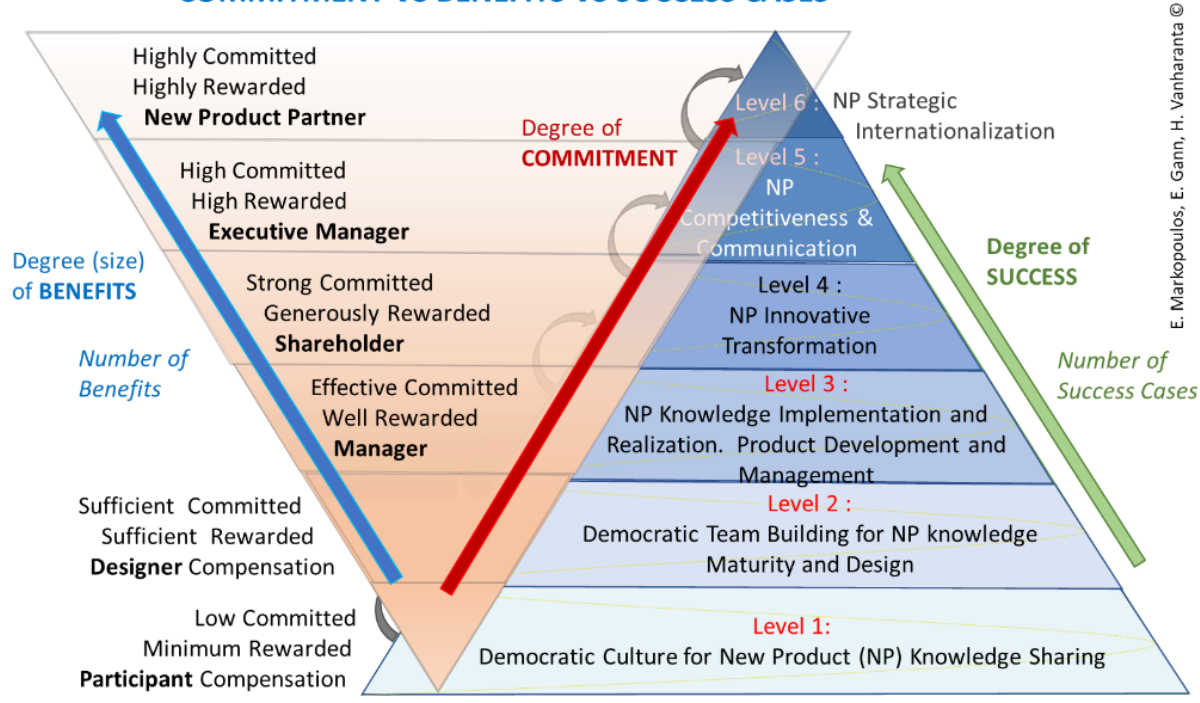

Fig. 3. The Democratic New Product Development Model (DeNPD)

The credibility and ethicality of the DeNPD Model relies on the DeNPD Company House, an intermediary independent authority, responsible for registering ideas generated by the society, as well as companies' product requests, and managing the matching between knowledge supply and demand.

The collaboration between companies and individuals extends the Company Democracy Model operations with the formation of a reversed pyramid in which the engagement and the benefits of the individuals are escalated. The DeNPD captures three essential relationships which are the success of the product, the degree of commitment of the individual, and the number of benefits/rewards an individual receives. At the early stages of this industry-society collaboration, the individual solely shares product ideas with the organisation on limited commitment and benefits. The commitment increase of the individual in the NPD process provides more opportunities, benefits and stabilizes collaboration relationships with the organization. The DeNPD allows the society to realize its product needs, openly, with equality, distribute earning rewards, reduces corporate $\mathrm{R} \& \mathrm{D}$ cost, and increasing innovation in a win-win framework.

This application of the Democratic NPD model in a green context eases the path towards Green Oceans with the utilization of intellectual capital energy invested by 
individuals ignored by the industry. By integrating the citizens in the process of idea generation for green product development, companies can reduce idea wastage and issue a better judgment on the relevance of ideas for sustainability and profitability.

\section{The DeGPD Model}

Based on the Democratic New Product Development (DeNPD) and the Green Innovation Waste Management Protocol (GIWMP), the Democratic Green Product Development (DeGPD) is being developed to ignite Green Capitalism. The DeGPD extends the Blue Ocean driven DeNPD on solving the critical for the human existence global environmental challenges and risks the world faces today with the implementation of Green Ocean Strategies in Green New Product Development. However, the transition from the Red to the Green Ocean without passing through the Blue Oceans can result in financial risks, if long term sustainability cannot be secured by the organization's operations. Thus, a third pyramid is integrated into the DeNPD model to empower Green Capitalism in which the 3S innovation triptych of the Green Ocean Strategy transforms the knowledge generated under the DeNPD through a green perspective (Fig. 4).

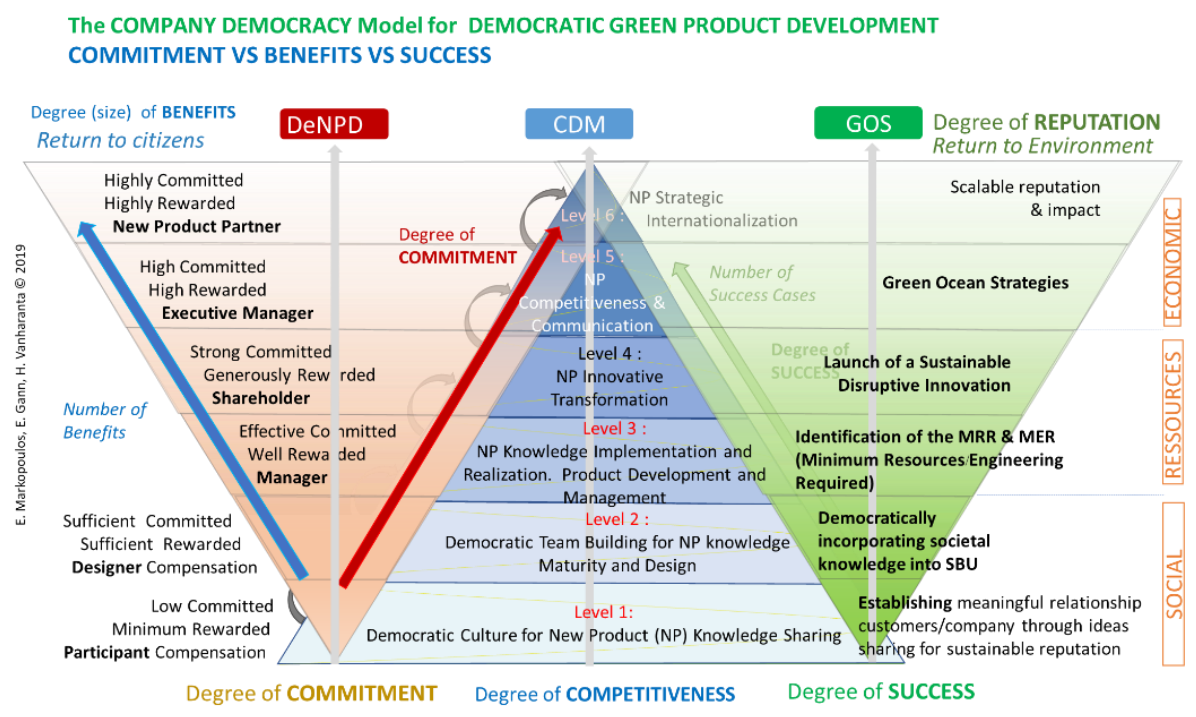

Fig. 4. The Democratic Green Product Development Model (DeGPD)

The citizens are encouraged to provide their green ideas and filter other ideas for their sustainability potential. Henceforth, ideas are not only valued by their profitability but also for their sustainability. The first level of the Green pyramid attempts to understand the green impact of a proposed new product. It is the state the product is introduced at a conceptual level and with limited impact due to the narrow contribution of the individual and its relatively small impact in the company. The second level demo- 
cratically constructs the team around the product idea, which enables to further determine and define its environmental impact and integrate the individual more in the company. In Level 3, the product gets developed under a green view, which increases its impact on the environment and the reputation of the company respectively. In Level 4, the green product is placed in the market and based on the positive environmental impact generated through customer purchases, further research and development is conducted to enhance its innovative elements. In Level 5, the new, innovative product is strategically marketed to deliver the competitiveness gained by its extended positive impact and reinforce the green reputation of the company. Lastly, in Level 6, the product utilizes its competitive advantage of level 5 to penetrate international markets, scaling its impact and reputation furthermore.

The overall journey and cooperation of the individuals (citizens) and the companies are driven by a rewarding scheme that intensifies from level to level the contribution and commitment of both parties on this process, allowing the company to fully utilize the people's understanding and knowledge for successful green innovation. The DeGPD model aims to find green elements in blue innovations. The further an organization moves up the stages, the more green elements can be identified, elevating the environmental impact and organizational reputation. Eventually, the DeGPD model allows organizations to place themselves into the Green Oceans, achieving profitability and sustainability coherence that enables long-term viability and success.

\section{Sustainable Green Capitalism}

The terminology of Green Capitalism has been floating in the literature in numerous attempts contested and re-conceptualized over the last few years. However, there has not been a case where the term is being used under the integration of sustainability with profitability, which explains the criticism in the press [15], [16].

In one of these definitions, Green Capitalism is expressed as "a form of environmentalism that emphasizes the economic value of ecosystems and biological diversity and attempts to reduce human environmental impacts by ensuring that the importance of environmental services is reflected in the way that markets operate" [17]. On that basis, the judgment from economic journalism is understandable: the notion of sustainability here is neither comprehensive nor practical. Henceforth, in a book titled Green Capitalism, why it can't work, Smith states that "If by Green Capitalism we understand a system in which the qualitative, social and ecological parameters are taken into account by the numerous competing capitals, that is to say even within economic activity as an endogenous mechanism, then we are completely deluded. In fact, we would be talking about a form of capitalism in which the law of value was no longer in operation, which is a contradiction in terms" [18]. The notion that long-lasting value creation is hydrophobic to capitalist can be possible rethought.

Beyond the literal common understanding of sustainability as ecologicalfriendly, corporate sustainability has to be understood as long-lasting value innovation. This is due to the fact that ecological sustainability can solely be achieved on the basis of corporate sustainability in regard to profitability, productivity and performance, allowing businesses to operate and impact the market in the long run. Since the 20th century, companies' mutation in size, geographical scope, and stakeholder integration makes them game-changers for the market and by extent for the society. The socio- 
cultural behavior co-evolves today under the company's omnipresence, which provides them with a degree of responsibility. Society's entities, movements, and other influence clusters drive indirectly company's actions. Under this perspective, successful companies have to mirror society and act as a possibilities revealing prism displayed under the innovation light. Therefore, companies can shift to sustainability as society, nations, and policies are acting towards.

It is, therefore, necessary for the academic literature to contribute towards establishing a definition consensus on the Green Capitalism term, meaning Sustainable Ecological Capitalism. This notion has to be a synonym to long-lasting value creation and scaled profitability from ecological initiatives, products and inventions.

Under this perspective, Green Capitalism needs to be redefined and reconsidered as a dimension of capitalism, aiming at organizational growth, productivity, profitability and performance, but also and simultaneously sustainable value innovation for the society, economy and environment, in which a viable company operates.

\section{Conclusion}

Green capitalism is not a contradictory term between activism and capitalism. In order to achieve environmental sustainability, it is important first to achieve corporate sustainability. In this relationship, capitalism links the positive development of companies with the positive development of the environment. It is a win-win relationship that needs to be embedded and accepted by both the activists, the ethical capitalists, and the profit-driven capitalists. To achieve this balance companies shall give more new products to the environment and the environment will then give more profits to the companies. Developing new green products benefits both the companies and the environment but, in this relationship, a third party is involved as an inflection point of the equation. The involvement of the citizen, the individual, is required in the development of these new green products. Today the individuals are more environmental consciousness than ever before can be the ultimate source of ideas for developing what can be bought while saving the planet. These new products can be achieved through the DeGPD, an extension of the DeNPD with the difference that the new products developed for green capitalism and shall be eco-friendly. The democratic concept of the DeGPD is based on the involvement of the society where actually anyone has the same opportunity to contribute intellectual capital towards the new definition of Green Capitalism. However, developing intellectual capital requires effort and energy that shall not be wasted. The Green Innovation Waste Management Protocol behind the DeGPD reduces the waste of such energy and enables more green intellectual capital to be implemented and impact the market by offering more green products for the sustainability of the companies and the environment. Green capitalism is the integrated outcome of Red, Blue and Green Ocean strategy, the Company Democracy Model, and the Democratic New Product development adjusted for the Democratic Green Product development. All these are orchestrated under an Innovation Waste Management Protocol which assures that no green knowledge and contribution will be wasted. Green Capitalism is Capitalism. It is the new capitalistic thinking and acting that can return to the people, the economy and the environment. 


\section{References}

[1] Rangan V. K et al.: Sustainability at IKEA Group. Harvard Business Review. November (2017).

[2] Harvard Business Review: https://hbr.org/1994/07/the-challenge-of-going-green, Retrieved on Nov.3, 2019.

[3] The Guardian: https:/www.theguardian.com/lifeandstyle/2019/jul/29/eco-friendly-goinggreen-poor-cost-diary Accessed on November 10, (2019).

[4] Gunn S.: The Buchanan Report, Environment and the Problem of Traffic in 1960s Britain, Twentieth Century British History, Volume 22, Issue 4, December 2011, pp 521-542. (2011).

[5] Paull J.: The Rachel Carson Letters and the Making of Silent Spring. SAGE Open July-September 2013: 1-12. (2013).

[6] Vox: https://www.vox.com/2019/9/17/20864740/greta-thunberg-youth-climate-strike-fridays-future. Retrieved on Nov.11, 2019

[7] Kim W. C., Mauborgne R:. Blue Ocean Strategy. Harvard Business Review. October 2004.

[8] Markopoulos E., Kirane I.S., Piper C., Vanharanta H.: Green Ocean Strategy: Democratizing Business Knowledge for Sustainable Growth. In: Ahram T., Karwowski W., Pickl S., Taiar R. (eds) Human Systems Engineering and Design II. IHSED 2019. Advances in Intelligent Systems and Computing, vol 1026. Springer, Cham (2020).

[9] Storyminers: https://storyminers.com/human-centered-design-toolkit-from-ideo/.

[10] Robertson B.: Holacracy: The New Management System for a Rapidly Changing World. Henry Hold \& Company, New York. (2015)

[11]. Forbes. https://www.forbes.com/sites/jacobmorgan/2015/07/22/the-complete-guide-5types-of-organizational-structures-for-the-future-of-work/\#1bbffb027705. Retrieved on Nov. 10,2019

[12] Markopoulos E., Vanharanta H.: Democratic Culture Paradigm for Organizational Management and Leadership Strategies - The Company Democracy Model. Proceedings of the 5th International Conference on Applied Human Factors and Ergonomics AHFE 2014 (2014).

[13] Levitt T.: Marketing Myopia. Harvard Business Review. July-August (2004).

[14] Markopoulos E., Gann E.L., Vanharanta H.: Democratizing New Product Development Through an Industry-Society Entrepreneurial Partnership. In: Ahram T., Karwowski W., Pickl S., Taiar R. (eds) Human Systems Engineering and Design II. IHSED 2019. Advances in Intelligent Systems and Computing, vol 1026. Springer, Cham (2019)

[15] Sweeney S.: Green Capitalism Won't Work. New Labor Forum. Volume: 24 issue: 2 , page(s): 12-17, (2015)

[16] BusinessInsider https://www.businessinsider.com/green-capitalism-is-a-myth-20159? $\mathrm{r}=\mathrm{US} \& I R=\mathrm{T}$. Retrieved on Nov.14, 2019

[17] Scales I.: The International Encyclopedia of Geography: People, the Earth, Environment, and Technology. John Wiley \& Sons. DOI: 10.1002/9781118786352.wbieg0488 (2017)

[18] Tanuro D.: Green Capitalism: Why It Can't Work. Fernwood Publishing. (2014) 